\title{
IMPACT - Traffic safety campaigns for young people
}

\author{
Daniel Vankov ${ }^{a}$, Clemens Kaufmann ${ }^{b}$ \\ ${ }^{a}$ Open Youth Institute for Research, Education and Development, 6 Kanarche Str., Sofia 1756, Bulgaria \\ ${ }^{b}$ FACTUM Chaloupka \& Risser OHG, Hermann-Bahr-Straße 9/11, 1210 Wien, Austria
}

\begin{abstract}
IMPACT is a European project that aims to promote road safety and explore synergies between all stakeholders in the participating countries (Bulgaria, Romania, Hungary, Belgium, Argentina and China). This will be achieved by project activities focused on relevant issues such as informal education and training. The goal is to help young people play an active part in society by making their main mobility modes (walking, cycling and/or motorcycle use) both safer and an integral part of their lives as responsible road users.

The Open Youth Institute for Research, Education and Development (iRED) trained youth workers and animators ${ }^{1}$ in the participating countries to plan and implement their own campaign. In order to ensure the
\end{abstract}

efficiency of these planned activities, FACTUM OG is serving as the project evaluator. The main evaluation tools used were questionnaires targeted at different actors (partners, youth workers, young people participating in the actions, stakeholders). The questionnaires were distributed at different stages of the project (evaluation phases). The results of the evaluation served as an information source for the obtained achievements as well as for revealing what aspects of the project campaigns, communication tools and dissemination strategies need to be improved.

Based on the first results of the evaluation the following was achieved in regards to the IMPACT main objectives:
Main objective

1. To choose and share good practices in road safety which will involve modern technologies (e.g. driving simulators) for attracting young people. Therefore each project partner will implement two local road safety campaign.

2. To train 18 youth workers (3 per partner country) and 30 young animators (1 team of 5 people per partner country) to successfully plan and implement youth-led awareness-raising campaigns targeting vulnerable road users.

3. To directly involve 600 citizens (100 per partner country, $50 \%$ in those with less opportunities) in the six local field campaigns organised by the young animators during the first implementation of the campaign. During the second implementation another 1.200 citizens should be reached (200 per partner country, 50\% in those with less opportunities; in total 1.800)

4. To reach at least 12.000 citizens via paper materials distributed during the campaigns, 50.000 citizens via the partners websites and 50.000 citizens via the media.

1 For the purposes of the IMPACT project an "animator" is a person that directly delivers the road safety action to the target group. i.e. "animates" or brings to life the road safety activities. They are different than youth workers as they do not engage with the respective organisation on full-time bases. They are also different from volunteers as they get remunerated for their efforts.
Achievements after the first implementation

During the two meetings so far (Kick-off and Mid-term meeting) the partners shared their previous experiences with traffic safety campaigns as well as their experiences with their implemented IMPACT campaigns.

In total 58 youth workers and animators were trained by iRED in 2015 .

In total 1.417 participants were directly reached by the different campaigns first implementations, more than double the target value.

The partners stated that they reached 20.358 people by using flyers and through their websites as part of their dissemination activities. More than 10.000.000 people were reached through conventional media (printed, online, TV and radio). The large number comes mainly from outreach in Bulgaria and China. In Bulgaria, iRED analysed the project media presence in 75 reviews. According to each media self-reported audience, information about the project potentially reached 3.502 .825 people. Similar methodology was applied by ZBH in China. $Z B H$ reported 730.000 reached by 4 printed materials and 5.615.400 unique visits online. The contribution of Social media to the dissemination is an additional 60.000 people reached. 
The article will give an overview of the:

- Project structure;

- Planned and carried out campaigns during the first implementation phase; and

- Main results of the different evaluations targeted at different people involved in the campaigns (partners, youth workers, young people participating in the actions, stakeholders).

KEYWORDS: Road safety; young people; vulnerable road users; prevention; International cooperation.

\section{INTRODUCTION}

Traffic safety is recognized as a global health issue. Accidents are the leading reason for fatal outcomes for young people between 15 and 29 years old and the eight leading one for deaths overall (WHO, 2015). No region makes a difference.

According to the "Road safety facts in the regions of the Americas" (WHO, 2013b) traffic injuries resulted in 149,992 deaths in the region in 2010. The average fatality rate was pushed up to 161 per million. Road traffic is the second leading cause of death for the people, aged 15 to 44, and the primary one for children aged 5 to 14 . Vulnerable road users (motorized two or three-wheelers, pedestrians and cyclists) are overrepresented with pedestrians accounting for $23 \%$, motorcyclists for $15 \%$ and bicyclists for $3 \%$ of the road fatalities.
The "Road safety in the Western Pacific Region" report (WHO, 2013c) reveals a particularly grave situation in the Western Pacific. In 2010, 336,439 fatalities occurred in the region with the rate of 185 per million population. Vulnerable road users account for $69 \%$ of the deaths: motorcyclists (36\%), pedestrians (25\%) and cyclists (8\%). These figures can be expected to rise with the increase in motor vehicle ownership in the region.

The European Union (EU) experiences the same problem but on another scale. Through a joint effort, focused policy and strategic planning over 102,000 lives were saved on the EU roads in the period 2001-2010 (ETSC, 2011). This is why EU praises itself as having the safest roads in the world. The fatalities were reduced by $43 \%$ (ETSC, 2011) for the period. This is a very good achievement although the strategic objective of "halving road deaths by 2010 " was not met. In addition for the same period serious injuries decreased by $36 \%$, all injuries by only $26 \%$ and accidents by mere $24 \%$ (Adminaite, Allsop, $\&$ Jost, 2015). This additional statistics suggests that the achievement may be less spectacular. In $2012 \mathrm{EU}$ was back on its track towards its 2020 goal of reducing the fatalities by $50 \%$. In that year deaths among unprotected road users represented $44 \%$ of all road deaths across the EU with pedestrians-killed - 20\%, cyclists $-6 \%$ and motorcyclists $-17 \%$ of all deaths (Jost, Allsop, \& Steriu, 2013). In 2016 the overall picture looks different. In 2014 annual reduction was only marginal marking the worst annual result since the start of EU targeted efforts back in 2001 (ECTS,

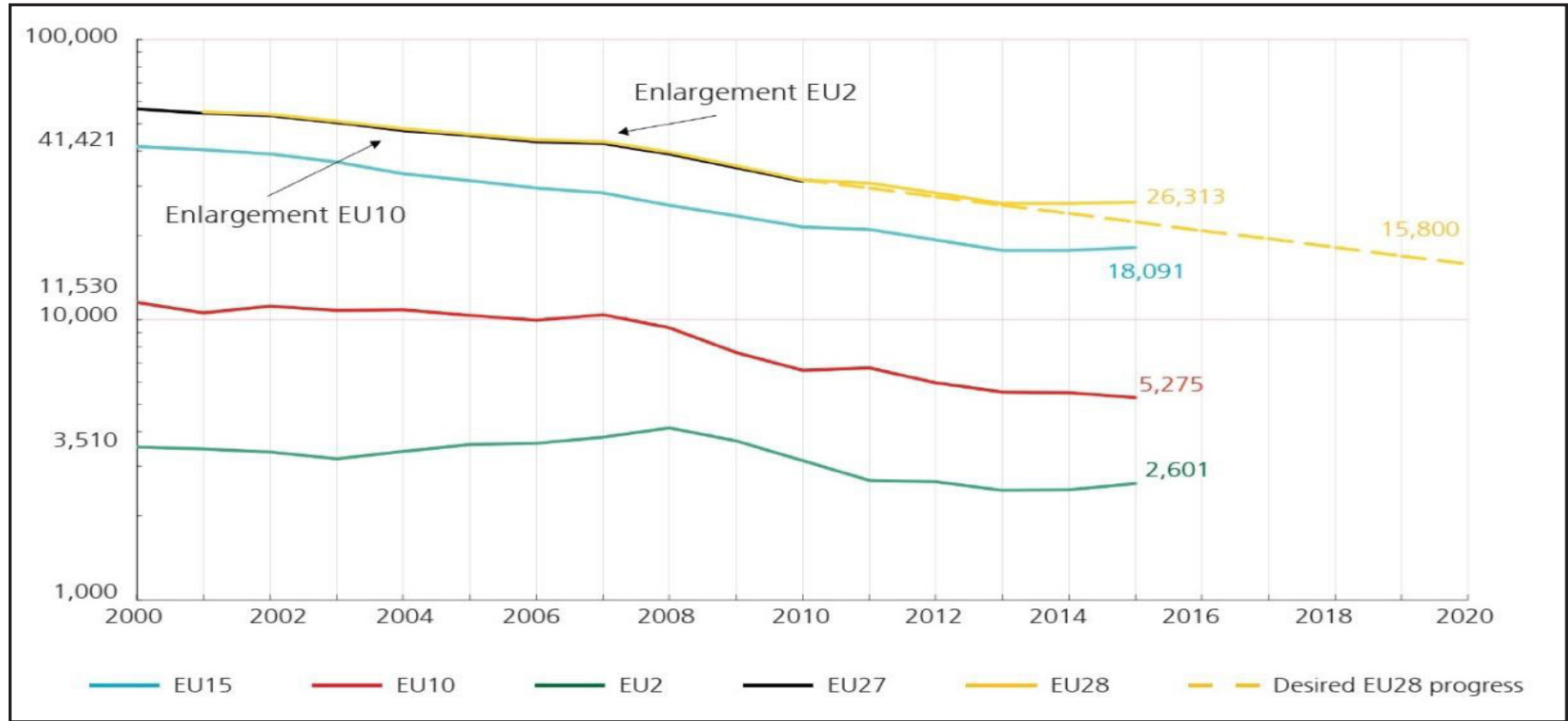

Figure 1: Number of road deaths since 2001 (Adminaite, Jost, Stipdonk, \& Ward, 2016) 
2015). EU needs an average of $6.7 \%$ annual reduction to reach its 2020 targets and the achievements are far from that (Adminaite et al., 2015). The yellow line on Figure 1 shows the road fatalities from 2001 to 2015. The yellow dotted line indicates the projected target line after 2010. For 2015, a widening discrepancy can be observed between the target number of road fatalities $(22,400$, yellow dotted line) and the recorded road fatalities $(26,313$, solid yellow line). For 2014 the respective numbers were 24,000 targeted number of road fatalities and 25,970 recorded ones. Although EU roads remain the safest in the world, the reversing trends call for immediate attention and innovative actions. The fact that EU road safety is better that anywhere else, including the regions reviewed above, should only motivate stakeholders for more efforts to keep this positive image.

Such unacceptably high level of fatalities and injuries negatively influences many young people's daily lives in relation to health, education, employment and well-being. A multitude of international initiatives on all levels have been developed and implemented in an attempt to address this issue. Several successful projects in Europe such as "Local Innovative adVentures to Ensure quality in youth road Safety promotion" (LIVES) and "Actions Corresponding to the Creativeness and local Opportunities in Road safety Development" (ACCORD) addressed one or more risk factors related to young traffic participants. In such projects a combination of appropriate Information and Communication Technology (ICT) deployment and peer-to-peer education was used. The gathered experience led to the development of an initiative that takes place simultaneously on three continents, the project "Involvement and Motivation for Participation of Active young Citizens to stand for Traffic safety" (IMPACT).

\section{STRUCTURE OF THE PROJECT}

The Global Status Report on Road Safety 2013 (WHO, 2013a) prompts that the hardest hit are middle income countries because of their rapid motorization. They account disproportionally high for fatalities per registered vehicle. Those countries have $52 \%$ of the vehicles and $72 \%$ of the population globally but register $80 \%$ of the traffic fatalities (WHO, 2013a). This is why IMPACT focuses on such countries in EU, Asia and Latin America to support not only reaching the 2020 EU road safety target of halving the road victims but also the UN Decade of Action for Road Safety 2011-2020. Those countries are Argentina, Belgium, Bulgaria,

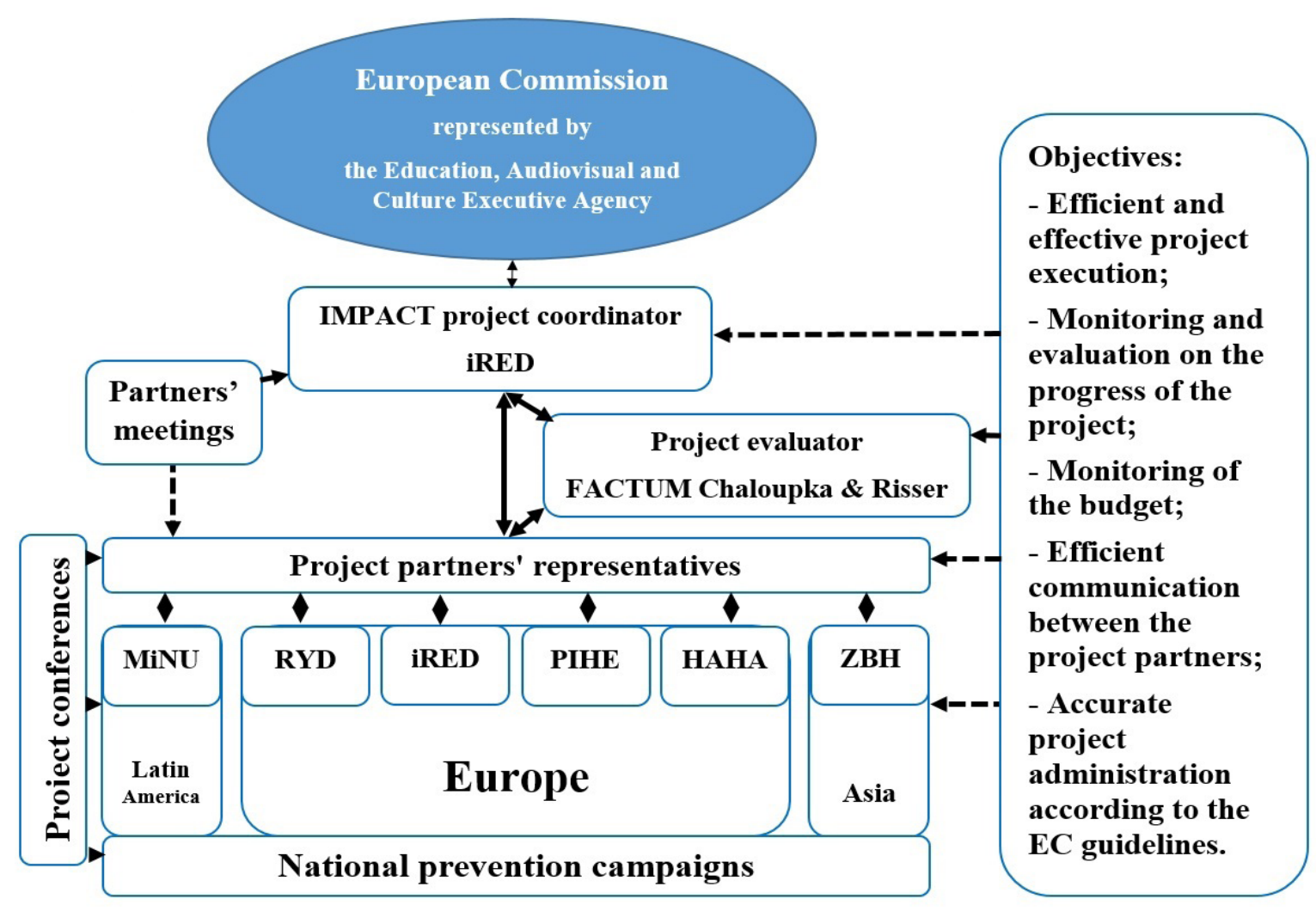

Figure 2: Structure of the IMPACT project 
China, Hungary and Romania. An experienced Austrian research institute adds value as a project evaluator (see Figure 2).

The aim of the IMPACT project is to boost international efforts to save young lives on the road by: 1) exchanging information and sharing good practices; and 2) providing a platform for long-term targeted impact through a list of exceptional players in the road safety and accident prevention field. The project fosters improvements in awareness raising with focus on the most vulnerable road users (youth, cyclists, children, etc.). It facilitates building of a better methodology through cross-fertilizing of intercontinental experience. The reason for the development of the IMPACT project is the need to implement a more holistic approach in solving contemporary social problems. The project recognises the need the approach to be based on available data and former experiences. However it also embeds a clear view of potential and a vision for the future. IMPACT explores the experience in involving youth in road safety promotion and accident prevention, learned through ACCORD and LIVES. The project implements the acquired knowledge where it has greatest potential for positive impact and is most needed. It promotes cooperation between stakeholders, with the goal to help young people to grow and play an active part in their society by making their main mobility modes (walking, cycling and/or motorcycle use) an integral part of their safer mobility.

\section{PREPARATION, TRAINING AND PLANNING OF THE CAMPAIGNS}

The concept of IMPACT presumes that the project partners do not have to "reinvent the wheel" in road safety. There are enough good practices from which ideas can be borrowed and adapted locally. To establish the ground for exchange of experience between the partners a Kick-off meeting was implemented from 25th to 28th of March 2015 in Vienna, Austria. All project partners sent their representatives to share their experience, discuss and develop the project strategy in details (project logic, visuals, evaluation, national campaigns, recruitment of animators, public relations). The meeting was very important as it set a tone of transparency and openness not only within the project consortium but also in its relations to other potentially interested road safety stakeholders. The project was tuned to share with the public all its achievements so that they can be used for further multiplication. This is happening through the project website (see Figure 3). The website exists in seven languages and each partner is responsible for supplying all information, relevant to its activities.

In an effort to streamline this diversity of experience and establish a common platform of road safety knowledge and understanding, a Training course for youth workers and animators was developed under the topic "Vulnerable road users". iRED prepared the course material using best practice material from

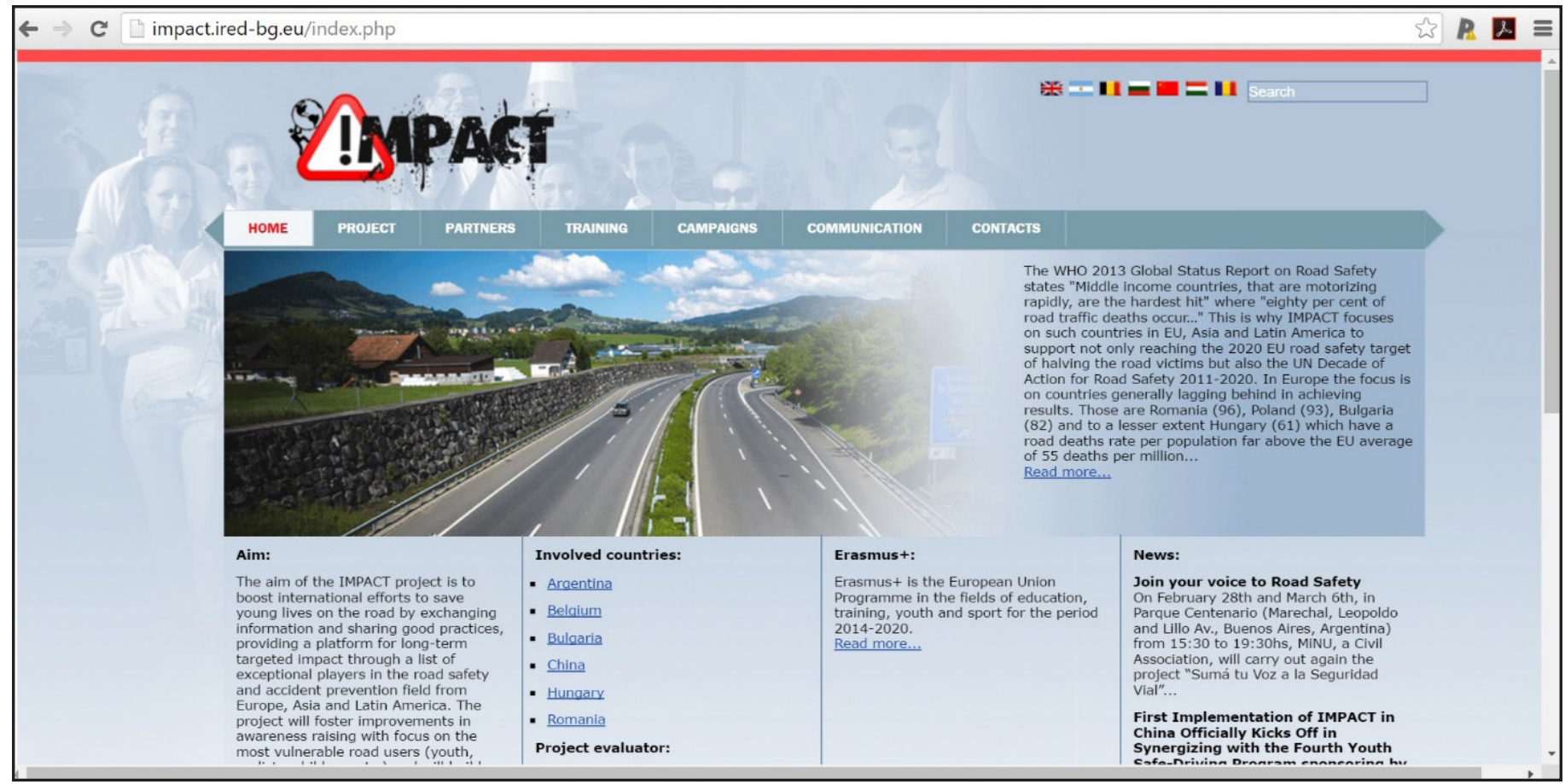

Figure 3: The IMPACT project website: $\underline{\text { http://impact.ired-bg.eu }}$ 
the "Road Safety in South East Europe" (ROSEE) project and Responsible Young Drivers' Formapack. A total of 270 slides covered a multitude of topics, including the IMPACT project itself, road safety fundamentals, vulnerable road users, pedestrian safety, bicyclists, powered two-wheeler drivers and young drivers. Special attention was dedicated to the last one. With that respect the training pack explores in deep the rage on the road, what we do before we sit behind the wheel, impaired vision, influence of speed, driving under influence, seatbelt and interactive simulations. iRED delivered the training course as follows:

- April 06th, 2015 in Oradea, Romania,

- April 07th, 2015 in Debrecen, Hungary,

- April 20th, 2015 in Buenos Aires, Argentina,

- May 19th, 2015 in Shanghai, China,

- July 03rd, 2015 in Brussels, Belgium and

- July 10 $10^{\text {th }}, 2015$ in Vidin, Bulgaria.

After the trainings the task for each partner was to pick their best performing campaign from their own experience and to further improve it by adapting new ideas and practices learned during the initial phases of the project. For example iRED picked for Bulgaria its flagship campaign "Drive responsibly and courteously". The aim of the campaign is to promote courtesy between drivers on the road thus ensuring safer environment for all traffic participants. The campaign is based on a special police operation using the broader control in combination with positive intervention of iRED representatives towards encouraging responsible driving and reduction of road aggression. Five animators are speaking to drivers and disseminating anti-stress figures as well as a project flyer. The campaign is implemented in cooperation with the Ministry of Interior on national level and Traffic Police departments on local one. The improved concept included:

- European experience by replacing the antistress ball with an anti-stress pill, thus underlining the danger of driving under influence of drugs, medicines and alcohol.

- South American experience by improving the visual concept of the flyer through adding a young male under the influence of alcohol who goes outside the road and crashes. The new visualization implies that there is only one "right" way to drive.
- Asian experience by improving the schedule of the actions in order to reach a maximum number of the project target group, i.e. young and vulnerable road users, during the time their vulnerability is increased.

In Argentina the campaign pushed the local partner outside its comfort zone of educational experiences involving road safety. Before IMPACT activities focused exclusively on methodologies and dynamics designed for young people in a classroom context. The IMPACT campaign went out in the open with banners and flyers containing a summary about the project and diverse information of road safety, road safety tests, reflex and concentration measuring games with alco-vision goggles.

In Belgium the campaign went to sport events and introduced prevention activities against driving under the influence of drugs with goggles simulating the effect of marijuana. The other focus was encouraging eco-driving through technologies analysing personal performance behind the wheel.

In China the campaign encouraged young people to understand and experience the concept of "safe driving" by learning five safe driving habits: no alcohol driving, no speeding, no distractions, driveway safety and use of safety belt. Volunteers from universities in Shanghai acted as ambassadors for interactive onsite activities. They encouraged more people to understand the importance of safe driving and to grasp the value of proper driving habits. Volunteers from the private sector were also engaged as young animators. The Traffic Police was involved as co-host of public advocacy events.

In Hungary the campaign focused on organizing road preventions in regional activities. It promoted road safety on major events (music festivals, city days, civic programs) and implemented a crash course campaign with the local Police Department. A new driving simulator was introduced in the framework of the project. Grammar school students who just begin to be independent traffic participants on bikes, scooters and cars were the largest directly involved group.

In Romania the campaign took the form of a permanently working Public Road Safety House. It aimed at training young people between 12 and 20 years of age about safe public road use. Due to the campaign success and the large number of visitors the association signed co-working contracts with elementary and secondary schools as well as student 
organizations from the universities in Oradea. The main essence of the concept is to offer the possibility of an interactive training in the theme of Public Road Safety with professional animators and youth workers. The training takes approximately one to one and a half hours. The campaign pays special attention not only to young people but also to other vulnerable road user groups such as cyclists, motorcyclists and beginner drivers. A new eco-driving simulator was supplied through the IMPACT project.

\section{EVALUATION}

An evaluation is an integral part of a project which monitors and improves the efficiency of a programme. The evaluation serves to support all stakeholders involved by increasing knowledge and communication in order for decision makers to make timely decisions regarding the implementation of programmes and to draw conclusions for policy making.

Different approaches, methodologies and tools may be used for the conduction of an evaluation. Indeed, there are several types of evaluations applicable to road safety campaigns, the two main forms being formative and summative evaluations (Frechtling, 2002; Herman, Morris, \& Fitz-Gibbon, 1987). The evaluation of IMPACT is conducted throughout the duration of the project. The evaluation consists of three evaluation phases (Preparative, First Implementation and Second Implementation, see Figure 4) which were carried out consecutively as follows:

- Evaluation 1 (EVA1 - formative evaluation): evaluation of the Preparative phase; started at the beginning of the project (March 2015) and lasted until the start of the First Implementation Phase (February 2016).

- Evaluation 2 (EVA2 - summative evaluation): evaluation of the First Implementation

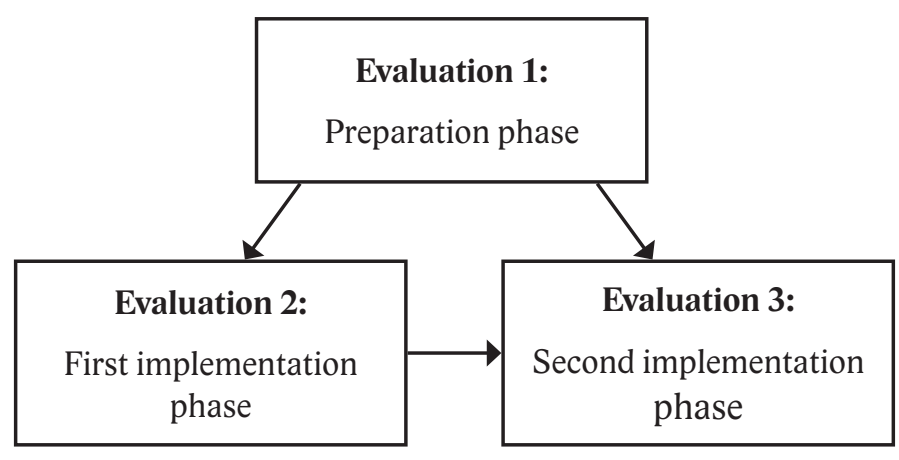

Figure 4: Overview of the three evaluation phases
Phase; started in September 2015 and ended in April 2016.

- Evaluation 3 (EVA3 - summative evaluation): evaluation of the Second Implementation Phase; started in April 2016 and will end in December 2016.

Each evaluation phase consists of separate questionnaires for different target groups. These questionnaires and the respective questions are presented in the following Table 1. Questions were developed, selected and modified according to the needs of the project partners and other project stakeholders, including questions related to the state of art of the evaluation processes. The questionnaires also collect information about the state of the general IMPACT goals. For instance, the questionnaires for Evaluation phase 2 were developed based on the Evaluation phase 1 results.

The formative evaluation set out a number of objectives to be achieved. Initially, information had to be collected about each partner's intervention. Subsequently an analysis had to be performed to determine the level of implementation at each phase. Building on the last, the evaluation aimed to verify the variables that affected the implementation and these will serve to assist future endeavours. Finally, the evaluation set out to collect information about the effectiveness of the intervention in the different countries involved. It should be noted that the geographical location of the partner countries (Europe, Asia and Latin America) provides a wide coverage and hence allows for a useful comparison to be made between different jurisdictions.

The main tool of the summative evaluation are the questionnaires of the first and second implementation phase. They underline the starting point and achievements of the project in relation to the target group. The collected data (only the first implementation was carried out so far) was used as an information source for improving the project campaigns, communication tools and dissemination strategy. The evaluation methodology is using a number of factors which serve as indicators of assessment/achievement throughout the project. These are as follows: the overall number of young people involved, the number of implemented activities, the volume of traditional media coverage, the comparison of the collected data from the two stages of national campaigns implementation; and the evaluation of the added value of the driving simulators and the eco-driving analyser to the achievements of previous related activities. 
Table 1: Overview of the questionnaires in evaluation phase 1

EVALUATION 1: Preparation Phase - Formative approach

\begin{tabular}{|c|c|c|}
\hline Action & Target group & Objectives \\
\hline $\begin{array}{l}\text { QUE } 1 \text { at the Kick-off } \\
\text { meeting }\end{array}$ & Project partners & $\begin{array}{l}\text { Evaluation of the general objectives of the project } \\
\text { - } \quad \text { Clarity and achievability of objectives and working steps }\end{array}$ \\
\hline $\begin{array}{l}\text { QUE } 2 \text { regarding the } \\
\text { implementation plans }\end{array}$ & Campaign leaders & $\begin{array}{l}\text { Evaluation of the implementation plan } \\
\text { - } \quad \text { Outline of the campaign, planned actions, dissemination } \\
\text { - Target group }\end{array}$ \\
\hline $\begin{array}{l}\text { QUE } 3 \text { regarding the } \\
\text { training of youth workers }\end{array}$ & $\begin{array}{l}\text { Youth workers } \\
\& \text { animators }\end{array}$ & $\begin{array}{l}\text { Evaluation of the iRED training } \\
\text { - } \quad \text { Information about the youth workers (background, motivation) } \\
\text { - } \quad \text { Satisfaction with the training and clarity of planned actions }\end{array}$ \\
\hline
\end{tabular}

EVALATION 2: First implementation Phase

\begin{tabular}{lll}
\hline Action & Target group & Objectives \\
\hline $\begin{array}{l}\text { QUE 4.1 regarding the } \\
\text { 1st implementation }\end{array}$ & Campaign leaders & $\begin{array}{l}\text { First evaluation of the campaign } \\
\end{array}$ \\
& $-\quad$ Objective numbers (number of actions, involved youth workers, \\
& contacted participants, distributed materials, dissemination activities) \\
&
\end{tabular}

QUE 5.1 regarding the Youth workers 1st implementation

QUE 6.1 regarding the 1st implementation

QUE 7.1 at the Mid-term meeting

\begin{abstract}
\& animators
\end{abstract}
Participants of the campaign

Participants of the Mid-term meeting
First evaluation of the effects of the campaign

- Satisfaction with the campaign and estimated satisfaction of the participants

- Possible problems

First evaluation of the effects of the campaign

- Background (means of transport, view on traffic safety)

- Satisfaction with the campaign and change regarding views on traffic safety

Evaluation of the 1st implementation of the campaign

- Satisfaction with the campaign

- Possible problems and suggestions for improvement
The final evaluation will consist of assessing the campaigns of each partner country after advice has been provided by the evaluators and improvements have subsequently been made. The evaluation will show the overall project achievements and will be used for dissemination activities on an International level. A final evaluation report will be sent to the European Commission together with the final report.

\section{RESULTS FROM THE DIFFERENT EVALUATION STEPS}

In the following the main results of the two evaluation phases which were carried out so far are presented. The following tables give an overview of the sample size as well as the gender and age distribution in the different questionnaire surveys so far.

\subsection{Sample description}

\section{Number of respondents (see Table 2)}

Questionnaires 1 (Kick-off meeting), 2 (planning of the campaign) and 4 (evaluation of the campaign) were filled in by the campaign leaders. Questionnaire 3 was completed by 58 youth workers and animators $^{2}$ who participated in the iRED trainings. 43 of them finally participated in the implementation of the campaigns and therefore filled in questionnaire 5. In total over 1.000 respondents filled in questionnaire 6 after participating in the different campaigns. Finally twelve stakeholders and partners completed questionnaire 7 during the Mid-term meeting.

2 Youth workers are people directly involved in the organsiation and therefore also in the organization and implementation of the campaign. Animators do not engage with the respective organisation on full-time bases but helped with the organization and implementation of the campaign. 


\section{Gender distribution}

While the campaign leaders were mostly men, the gender distribution of the youth workers and animators who carried out the campaigns was almost equally distributed. But it has to be said that in Hungary mainly female youth workers and in Romania mainly male youth workers were implementing the campaigns. The results of the gender distribution of the participants showed that in all countries more men than women filled-in a questionnaire. In most of the countries the difference is under $10 \%$, except in Belgium and Bulgaria were much more men completed the questionnaire (see Table 3).

\section{Age distribution}

Youth workers and animators predominantly under the age of 30 years participated in the trainings and also carried out the actual campaigns. The age distribution of the participants differ from country to country (see Table 4). In China, Hungary and Romania almost $100 \%$ were under 30 years of age because the campaigns were held either at universities, schools or

Table 2: Overview of the different questionnaires and number of respondents per country and in total

\begin{tabular}{lccccccc}
\hline & Argentina & Belgium & Bulgaria & China & Hungary & Romania & Total \\
\hline QUE 1 at the Kick-off meeting & 1 & 1 & 1 & 1 & 1 & 1 & $\mathbf{6}$ \\
QUE 2 regarding the implementation plans & 1 & 1 & 1 & 1 & 1 & 1 & $\mathbf{6}$ \\
QUE 3 regarding the training of youth workers & 9 & 11 & 9 & 8 & 13 & 8 & 58 \\
QUE 4 regarding the 1st implementation & 1 & 1 & 1 & 1 & 1 & 1 & $\mathbf{6}$ \\
QUE 5 regarding the 1st implementation & 6 & 6 & 8 & 9 & 7 & 7 & $\mathbf{4 3}$ \\
QUE 6 regarding the 1st implementation & 169 & 102 & 249 & 90 & 237 & 169 & $\mathbf{1 . 0 1 6}$ \\
QUE 7 at the Mid-term meeting & & & & & & & 12 \\
\hline
\end{tabular}

Table 3: Overview of the different questionnaires and gender distribution of respondents per country and in total

\begin{tabular}{|c|c|c|c|c|c|c|c|c|c|c|c|c|c|c|}
\hline & \multicolumn{2}{|c|}{ Argentina } & \multicolumn{2}{|c|}{ Belgium } & \multicolumn{2}{|c|}{ Bulgaria } & \multicolumn{2}{|c|}{ China $^{1}$} & \multicolumn{2}{|c|}{ Hungary } & \multicolumn{2}{|c|}{ Romania } & \multicolumn{2}{|c|}{ Total } \\
\hline & $\hat{0}$ & 우 & 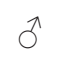 & q & $0^{\lambda}$ & $q$ & $\hat{0}$ & q & $\sigma^{\lambda}$ & q & $\hat{0}$ & q & $0^{\lambda}$ & q \\
\hline QUE1 & 1 & & 1 & & 1 & & & 1 & 1 & & 1 & & 5 & 1 \\
\hline QUE2 & 1 & & 1 & & 1 & & & 1 & 1 & & 1 & & 5 & 1 \\
\hline QUE3 & 5 & 4 & 6 & 5 & 6 & 3 & 2 & 6 & 7 & 5 & 8 & & 34 & 23 \\
\hline QUE4 & 1 & & 1 & & 1 & & & 1 & 1 & & 1 & & 5 & 1 \\
\hline QUE5 & 3 & 3 & 3 & 3 & 5 & 3 & 4 & 4 & 1 & 6 & 6 & 1 & 22 & 20 \\
\hline QUE6 ${ }^{2}$ & 52 & 48 & 71 & 29 & 85 & 15 & 53 & 47 & 60 & 40 & 52 & 48 & 62 & 38 \\
\hline
\end{tabular}

${ }^{1}$ One missing, ${ }^{2}$ as a percentage

Table 4: Overview of the trainings and campaigns questionnaires and age distribution of respondents per country and in total

\begin{tabular}{|c|c|c|c|c|c|c|c|c|c|c|c|c|c|c|}
\hline & \multicolumn{2}{|c|}{ Argentina } & \multicolumn{2}{|c|}{ Belgium } & \multicolumn{2}{|c|}{ Bulgaria } & \multicolumn{2}{|c|}{ China } & \multicolumn{2}{|c|}{ Hungary } & \multicolumn{2}{|c|}{ Romania } & \multicolumn{2}{|c|}{ Total } \\
\hline & $<30$ & $>30$ & $<30$ & $>30$ & $<30$ & $>30$ & $<30$ & $>30$ & $<30$ & $>30$ & $<30$ & $>30$ & $<30$ & $>30$ \\
\hline QUE3 & 8 & 1 & 9 & 2 & 6 & 3 & 1 & 7 & 5 & 8 & 4 & 4 & 33 & 25 \\
\hline QUE5 & 5 & 1 & 5 & 2 & 5 & 3 & 9 & & 4 & 3 & $4^{1}$ & $2^{1}$ & 32 & 11 \\
\hline QUE6 ${ }^{2}$ & 79 & 21 & 73 & 27 & 42 & 58 & 99 & 1 & 97 & 3 & 96 & 4 & 81 & 19 \\
\hline
\end{tabular}


student events where the focus was mainly on students and pupils. In Argentina and Belgium the events were organized on public places and around three quarters of the participants were under 30 years of age. Only in Bulgaria where the target group was car drivers "only" $42 \%$ of the people reached were under 30 and therefore were in line with the target group of the project.

\subsection{Results of QUE 1: Questionnaire at the Kick-off meeting}

After the Kick-off meeting the IMPACT partners' representatives were asked to fill in a short questionnaire and assess the quality of the received information. The results (see Table 5) showed that objectives of the project, the role of each one and the information given was clear and sufficent for the partners.

Nevertheless the partners also expressed some concers after the meeting:

- How can more cross-fertilisation of partner experiences be achieved?
- The project has too long timeframe (two years) and animators and youth workers may drop out.

- How to achieve maximum quality assurance?

- What gender distribution among animators should to be targeted?

\subsection{Results of QUE 3: Questionnaire regarding the training of youth workers \& animators}

After each training, carried out by iRED, the participating youth workers and animators were asked to fill in a questionnaire with the aim to evaluate the effectiveness of the training. In total 58 youth workers and animators in the different countries (see Table 6) completed the questonnaire.

In general the training was percieved as very good. The youth workers and animators agreed over $90 \%$ to questions regarding the training itself (general satisfaction, new things learned, recommendation to repeat the training for others). Also questions regarding the project (clear objectives, working steps, planning, confidence to carry out the

Table 5: Kick-off meeting scorecards summary

\begin{tabular}{lc}
\hline Question & Average score* \\
\hline Are the objectives of the project clear? & 4,9 \\
Is your role in the project clear? & 4,9 \\
Was the information regarding the training by iRED sufficient? & 4,9 \\
Are the working steps of the project clear? & 4,7 \\
In your opinion, are the objectives achievable? & 4,7 \\
Is the timeframe achievable? & 4,7 \\
Was the information about the recruitment of trainers and volunteers clear? & 4,1 \\
Was the objective concerning the cross-fertilisation of partner experiences sufficient? & 3,7 \\
\hline
\end{tabular}

* Likert scale $1=$ worse to $5=$ best

\section{Table 6: Trainings implementation feedback}

\begin{tabular}{lc}
\hline Question & \% of agreement \\
\hline Were you generally satisfied with the training programme? & 98,2 \\
Did you learn something new from the training? & 91,2 \\
Do you think that youth workers should generally undergo a training like this? & 89,5 \\
Are the objectives of the project clear? & 94,7 \\
Training helped to plan the campaign & 93,0 \\
Next working steps clear? & 93,0 \\
Following the training are you confident in carrying out the campaign? & 96,5
\end{tabular}


campaign) get an positive response of over $90 \%$ of the participants. Nevertheless, the youth workers and animators also had also some concerns after the training related to the:

- Gender distribution among youth workers and animators;

- Length of the training; and

- Length of the project.

\subsection{Results of QUE4 \& QUE 5.1: Questionnaire regarding the first implementation of the campaign (campaign leaders and youth workers)}

The campaign leaders and the youth workers received similar questionnaires (QUE4 \& QUE5) with the request to fill it in after the implementation of the campaigns. Besides the questions about satisfaction with the planning and implementation of the campaigns and the estimated satisfaction of the participants, the coordinators were additionally asked about campaigns objective numbers (number of participants, dissemination actions, etc.). The six campaign lead- ers and 43 youth workers and animators completed the questionnaire.

Youth workers and animators as well as the campaign leaders were satisfied with the organisation of the campaigns (see Figure 5). The numbers in the brackets next to the names of the countries represent the number of people (youth workers and animators) that completed QUE5. The scale used to answer the question "Overall, how satisfied were you with the organisation of the campaign?" ranges from " 1 " which stands for "Very satisfied" down to " 5 " which means "Not satisfied at all". The different colour bars depict how many people gave each respective answer. The number above the bars for each country represents the score given by the campaign leaders in each respective country.

The youth workers and animators were also convinced that their campaign was very well received by the participants and that it will have an effect on the participant's view on traffic safety. Furthermore, almost all youth workers and animators stated that they are encouraged to participate once again in another traffic safety campaign (see Table 7).

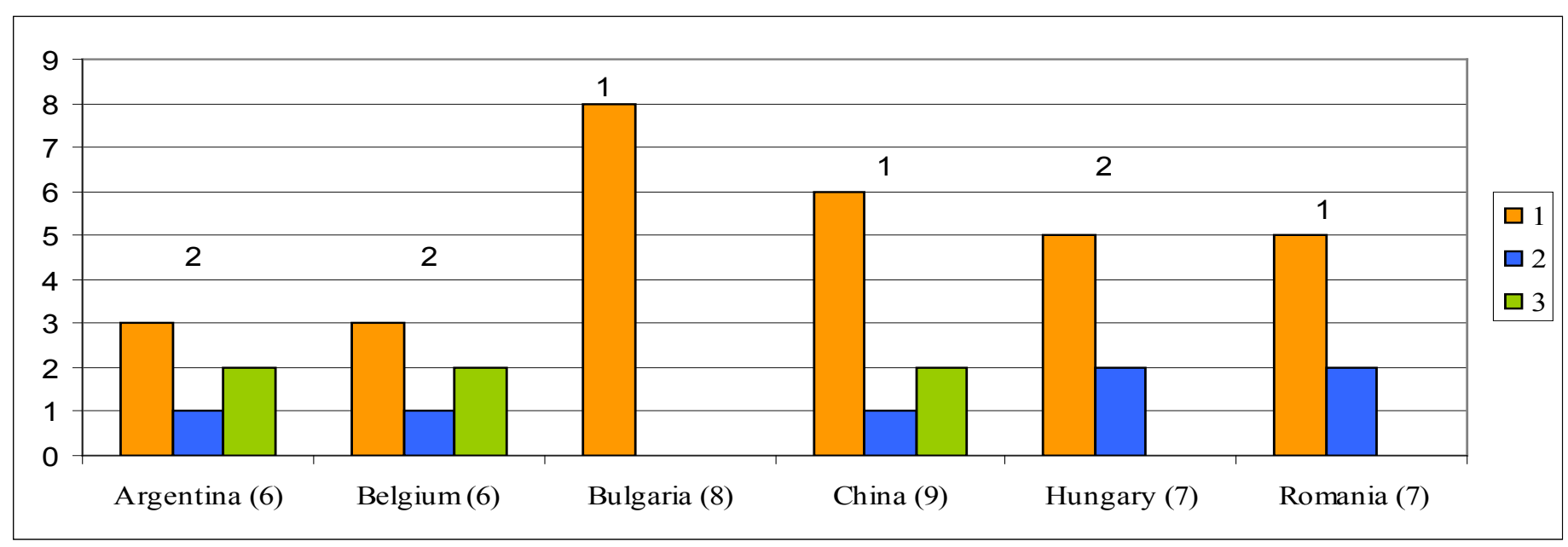

Figure 5: Satisfaction with the organization of the campaigns

Table 7: Views on the campaigns impact

\begin{tabular}{|c|c|c|c|c|c|}
\hline & 1 & 2 & 3 & 4 & Total \\
\hline $\begin{array}{l}\text { How was the campaign received by the participants? } \\
1=\text { "Very good" to } 5=\text { "Not good at all" }\end{array}$ & 24 & 18 & 1 & & 43 \\
\hline $\begin{array}{l}\text { Do you think that such a campaign will change the } \\
\text { participant's view on traffic safety? } \\
1=\text { "A lot" to } 5 \text { = "Not at all" }\end{array}$ & 21 & 20 & 2 & & 43 \\
\hline $\begin{array}{l}\text { Based on your experience, would you be encouraged to } \\
\text { participate in another traffic safety campaign? } \\
1=\text { "A lot" to } 5=\text { "Not at all" }\end{array}$ & 36 & 5 & 1 & 1 & 43 \\
\hline
\end{tabular}


Regarding the question what worked best during the campaigns the youth workers and animators mentioned that the games and interactive activities with the young participants were very useful. Also the direct contact and positive approach towards people helped them to present their messages. It was further stated that different tools such as simulators or fatal-vision goggles were very popular among the participants. Finally, it was also expressed that the good teamwork (also with authorities) and team spirit among the group of youth workers and animators helped to carry out a successful campaign.

Nevertheless, problems during the organisation and implementation of the campaigns were expressed, too. They were related to the:

- Too long period between the training and the actual event;

- Organisation process during the campaign;

- Lack of participants; and

- Too many activities during the event.

\subsection{Results of QUE 6.1: Questionnaire regarding the first implementation of the campaign (participants)}

More than 1.000 visitors filled-in a questionnaire after participating in the different campaigns in the six countries. In general the participants had a positive view on the campaigns (see Table 8). In all countries more than $70 \%$ stated that they learned something new. The exception was Argentina where a similar campaign with TV spots was launched at the same time. The issues presented by the youth workers and animators were also clear for the participants (agreement over $70 \%$ in all countries). Regarding the question if the view on traffic safety changed for the par- ticipants themselves, around two thirds expressed that the campaign had a positive effect (exception was again Argentina with 50\% agreement). Similar to that the respondents were of the opinion that the campaign had a positive influence on the view on traffic safety for other participants, too. Finally, more than $70 \%$ of the respondents in each country were encouraged to participate in another traffic safety campaign.

\section{CONCLUSION}

\subsection{General Conclusions}

During the first year of its term the IMPACT project was successfully implemented. It managed to provide space for capacity building through both crossfertilization and innovation. It allowed awareness on different road-related risks to be raised among large numbers of young traffic participants (1.417 direct participants and 58 youth workers and animators). The general satisfaction level is very high (see Tables 6 and 7 and Figure 5 above).

The evaluation results allow the following conclusions about the project experience to be made:

- The chosen intervention methods on national level were able to influence the targeted problematic road behaviour.

- The target group for the campaigns was well defined and effectively reached by the chosen activities.

- The project achieved its first stage objectives and already overachieved some of the overall ones.

- The project proved that experience from former projects is transferable to other contexts and can be successfully applied.

Table 8: Percentage of participants' positive replies to the respective question

\begin{tabular}{|c|c|c|c|c|c|c|}
\hline & Argentina & Belgium & Bulgaria $^{1}$ & China & Hungary & Romania \\
\hline $\begin{array}{l}\text { Did you learn something new due to the } \\
\text { campaign? }\end{array}$ & $56 \%$ & $75 \%$ & $81 \%$ & $70 \%$ & $81 \%$ & $90 \%$ \\
\hline Were the issues of the campaign clear to you? & $85 \%$ & $70 \%$ & & $71 \%$ & $95 \%$ & $94 \%$ \\
\hline Have your views on traffic safety changed? & $50 \%$ & $67 \%$ & $84 \%$ & $62 \%$ & $77 \%$ & $86 \%$ \\
\hline $\begin{array}{l}\text { Campaign will change the participant's view on } \\
\text { traffic safety? }\end{array}$ & $72 \%$ & $58 \%$ & & $71 \%$ & $76 \%$ & $90 \%$ \\
\hline $\begin{array}{l}\text { Would you be encouraged to participate in } \\
\text { another traffic safety campaign? }\end{array}$ & $81 \%$ & $76 \%$ & & $70 \%$ & $86 \%$ & $90 \%$ \\
\hline
\end{tabular}

${ }^{1}$ In Bulgaria a short version of the questionnaire was used and not all questions were asked. 


\subsection{Specific recommendations}

Despite the overall good impressions from the project implementation so far, as descrived above, some concerns related to possible problems and risks were expressed at different stages of the implementation. Here are recommendations in relation to:

- More cross-fertilisation of partner experiences: Partners should produce a short information document regarding their recent projects/ campaigns with the following content: objectives, activities carried out, target group and outcomes. This document should be distributed among the partners. The other partners should respond if these documents are useful to them and what use they can make of them.

- Animators may drop out:

Train more people in order to overcome possible drop-outs of youth workers and animators. Time for training new animators should also be foreseen after the implementation of the first campaign phase. Involve at least one person more than envisaged in each partner organisation who will be familiar with the project and can train new animators later.

- Quality assurance:

The partners should present their planned campaign to the other project partners and ask for feedback. Amend the campaign before the second implementation phase taking in consideration the feedback of the partners and evaluators.

- Gender distribution among youth workers and animators:

It would be good to have equal number of men and women acting as youth workers and animators. Past experiences showed that sometimes it is easier for men to convince women about the importance of traffic safety and vice versa for women to talk to men about traffic safety issues.

- Length of the training:

The training was seen as too packed and that one day is too short to receive all the information. Therefore, the suggestion for the future is to have a two-day training. A general overview on traffic safety can be given on the first day. Presentation of special issues and organisation of practical exercises according to them can happen on the second day.
- Length of the project:

Both the youth workers and the animators had the opinion that the length of the project might be too long and that there is a risk that some of the youth workers and animators will drop out during the project. Besides the suggestion to train more people from the beginning, it was also stated that team building measures should be implemented in order to enhance the group spirit and the in-group communication.

- Period between the trainings and the actual events:

The period between the training and the implementation of the campaign was perceived as too long. In the future this period should be shortened in order to keep the content of the training fresh.

- Organisation process during the campaign: Youth workers and animators should practice before the event in order to smoothen the organisation and processes during the campaign.

- Lack of participants:

The campaign should be advertised as much as possible. Advertising is seen as a key factor to gather more participants. Facebook, Twitter, flyers and posters should be used to promote activities. The campaign should also be organised during time when the participation of many people can be ensured. Therefore, the dates of the event and the timetable on the actual day should be chosen in such a way that it is certain that as many people as possible could be reached.

- Too many activities during the event: Personal contacts with the participants are suffering due to a full schedule and participants cannot take too much information with them. A possible solution is to involve more animators or to reduce the number of activities per event.

\subsection{Future work}

It will be interesting to see how the project develops in view of the newly acquired experience by the project partners as well as the provided recommendations. Evaluation phase 3 will provide good basis for comparison of achievements and shall reveal results worth of further investigation and dissemination. 


\section{FUNDING}

The IMPACT project has been co-funded by the European Commission Erasmus+ Programme. The current article reflects the views only of its authors, and the Commission cannot be held responsible for any use which may be made of the information contained therein.

\section{REFERENCES}

Adminaite, D., Allsop, R., \& Jost, G. (2015). 9th Road Safety Performance Index Report. European Transport Safety Council.

Adminaite, D., Jost, G., Stipdonk, H., \& Ward, H. (2016). 10th Road Safety PIN Report.

European Transport Safety Council. (2011). 5th Road Safety PIN Report.

European Transport Safety Council. (2015). EU road safety targets at risk as deaths increase in France, Germany and UK. Pressrelease.

Frechtling, J. (2002). The 2002 User-Friendly Handbook for Project Evaluation.

Herman, J. L., Morris, L. L., \& Fitz-Gibbon, C. T. (1987). Evaluator's handbook (Vol. 1): Sage.

Jost, G., Allsop, R., \& Steriu, M. (2013). 7th Road Safety PIN Report.

World Health Organization. (2013a). Global status report on road safety 2013.

World Health Organization. (2013b). Road safety facts in the regions of the Americas.

World Health Organization. (2013c). Road safety in the Western Pacific Region.

World Health Organization. (2015). Global status report on road safety 2015 . 